\title{
BMJ Open Adjusting working conditions and evaluating the risk of infection during the COVID-19 pandemic in different workplace settings in Germany: a study protocol for an explorative modular mixed methods approach
}

\author{
Esther Rind (D) , ${ }^{1}$ Klaus Kimpel, ${ }^{2}$ Christine Preiser, ${ }^{1,3}$ Falko Papenfuss, ${ }^{2}$ \\ Anke Wagner, ${ }^{1}$ Karina Alsyte, ${ }^{2}$ Achim Siegel, ${ }^{1}$ Antje Klink, ${ }^{2}$ Benjamin Steinhilber, ${ }^{1}$
} Johanna Kauderer, ${ }^{2}$ Monika A Rieger ${ }^{1}$

To cite: Rind E, Kimpel K, Preiser C, et al. Adjusting working conditions and evaluating the risk of infection during the COVID-19 pandemic in different workplace settings in Germany: a study protocol for an explorative modular mixed methods approach. BMJ Open 2020;10:e043908. doi:10.1136/ bmjopen-2020-043908

- Prepublication history and additional material for this paper is available online. To view these files, please visit the journal online (http://dx.doi.org/10. 1136/bmjopen-2020-043908).

Received 18 August 2020 Revised 19 0ctober 2020 Accepted 30 0ctober 2020

D) Check for updates

(c) Author(s) (or their employer(s)) 2020. Re-use permitted under CC BY-NC. No commercial re-use. See rights and permissions. Published by BMJ.

For numbered affiliations see end of article.

\section{Correspondence to}

Dr Esther Rind;

esther.rind@med.uni-tuebingen. de

\begin{abstract}
Introduction Currently, many countries, affected by the COVID-19 pandemic, discuss how the 'lockdownrestrictions' could be lifted to restart the economy and public life after the first wave of the COVID-19 disease has subsided. This study protocol describes an approach designed to provide an in-depth understanding of how companies and their employees in Germany deal with their working conditions during the COVID-19 pandemic. We are also interested in how and why the risk of infection with SARS-CoV-2 could vary across different professional activities, company sites and regions with different epidemiological activity or infection control measures in Germany. We expect the results of this study to contribute to the development of working conditions protecting the health of employees during and beyond the COVID-19 pandemic.

Methods and analysis An explorative multimodal mixed methods approach will be applied. Module 1 comprises a document analysis of prevailing federal and regional laws and regulations at the respective location of the participating company. Module 2 includes qualitative interviews with key actors at different companies. Module 3 is a repeated standardised employee survey designed to capture potential changes in the participants'

Strength and limitations of this study

One of the first studies to provide a comprehensive understanding of how companies implement and employees perceive and accept the 'new normal' regarding working conditions in Germany during the COVID-19 pandemic.

- The linkage of complementary methods (document analysis, interviews with company stakeholders, employee surveys, testing of antibodies against SARS-CoV-2) will allow an in-depth exploration of work practices and experiences in relation to occupational safety regulations/measures, infection control regulations/measures, and the actual and perceived risk of infection.

- Depending on the areas of interest and resources of the participating companies, the modular approach enables the implementation of up to four substudies, also allowing for a cross-sectional or a longitudinal study design.

- The implementation of multiple modules requires comprehensive resources in terms of time, qualified scientific staff and the organisation of the cooperation with different company sites as well as different companies.
\end{abstract} experiences and attitudes towards working conditions, occupational safety regulations/measures, and infection control measures during the COVID-19 pandemic. Module 4 comprises SARS-CoV-2 seroprevalence testing. This is carried out by the medical service of the participating company sites as a voluntary offer for employees. Qualitative data will be analysed through document and content analysis. The complexity of the quantitative analysis depends on the response rates of modules 3 and 4.

Ethics and dissemination The approval of the study design was received in June 2020 from the responsible local ethical committee of the Medical Faculty, University of Tübingen and University Hospital Tübingen (No. 423/2020B0). The results will be presented at national and international conferences and published in peer-reviewed journals.

\section{INTRODUCTION}

Background

At the beginning of 2020, the disease COVID19 , triggered by the coronavirus SARS-CoV-2, has developed into a pandemic. ${ }^{1}$ Without specific therapeutics or an effective vaccine available in the first quarter of 2020, many healthcare systems and governments 
responded to the rapid spread of the virus and the significant lethality of COVID-19 with the traditional means of containment: identification of cases and if necessary treatment under quarantine conditions, contact tracing and isolation of suspect cases, closure of schools and other educational institutions, non-system-relevant public institutions and businesses. In addition, most of the governments imposed contact restrictions and curfews considerably affecting everyday life of the population. For such a package of measures, the term 'lockdown' has become established. A lockdown lasting several weeks does not only result into a temporary restriction of civil rights such as freedom of assembly, but also into a considerable impairment of the economy. ${ }^{2-5}$ Currently, debates revolve around which conditions and in which way the 'lockdown-restrictions' could be lifted to restart the economy and public life after the first wave of the COVID-19 disease has subsided. This poses new challenges for local and global society: How can restrictions be relaxed without triggering another, even stronger and possibly uncontrollable wave of infection? Under these conditions, enterprises cannot simply 'go back to business as usual' ${ }^{2}$ and national and international recommendations regarding occupational health and safety standards tailored to the risks of SARS-CoV-2 infection have been developed. ${ }^{6-8}$ The term 'new normal' arose, meaning that as long as there will be no vaccination for SARS-CoV-2 and no effective treatment, the state of exception will last, including implementation of and adherence to strict hygiene measures, as well as social and physical distancing in private life and workplaces for individual and collective protection.

New studies on coronaviruses and COVID-19 have explored a variety of safety-related dimensions including social public safety, psychological health and domestic safety, medicine treatment and vaccine safety or the occupational safety of employees. ${ }^{9}$ The latter focuses particularly on working conditions and safety of healthcare professionals in clinical or ambulant settings. ${ }^{10-12}$ Furthermore, research has looked at COVID-19 stressors on migrant workers ${ }^{13}$ and commercial drivers, ${ }^{14}{ }^{15}$ and at measures to control the spreading of the corona virus in workplaces including engineering and administrative controls (eg, proper ventilation, restricting staff gatherings) as well as the provision of personal protective equipment (eg, protective masks or clothing). ${ }^{16}$ As of yet, we are not aware of any studies linking different data sources, perspectives and methods to provide an in-depth understanding in which ways companies and their employees deal with their working conditions during the COVID-19 pandemic and how different experiences and attitudes may impact variations in the occurrence of infections with SARS-CoV-2. The results of our study are expected to facilitate the effort of companies and executive managers to protect the health of their employees over the course of the COVID-19 pandemic, also preparing them for future challenges such as the next wave of influenza.

\section{Study aim and research questions}

The Institute of Occupational and Social Medicine and Health Services Research (IASV), University Hospital Tbingen, aims to explore how companies in Germany adjust to new occupational health and safety standards designed to prevent the spreading of the COVID-19 disease. We will focus on the following research questions:

1. Under which prevailing regulations and recommendations are working conditions adjusted in different workplace settings in Germany?

2. How do employers and their employees in Germany assess and accept their 'new normal'?

3 . How and why could the risk of infection vary across different German company sites and professional activities?

\section{METHODS AND ANALYSIS}

Previous contact of the IASV to representatives of the initially participating company's chief medical services resulted in the development of a cooperative project exploring occupational health and safety issues related to the COVID-19 pandemic. The transdisciplinary project group has academic and practical expertise in occupational medicine, health sciences, health services research and sociology and jointly discussed and developed the realisation of the study design in the participating company.

\section{Study design}

The IASV conceptualised an explorative multimodular mixed methods approach ${ }^{1718}$ following the guidelines "Good Reporting of a Mixed Methods Study" (GRAMMS - online supplemental file 1) developed by O'Cathain et $a l .{ }^{19}$ Mixed method designs have become an integral part of health-related and health services research, providing a variety of quantitative and qualitative tools complementing each other in order to gain a comprehensive understanding of complex research questions. ${ }^{19} 20$ The approach comprises three modules (modules 1-3 in figure 1) which can be applied either as an entire set, or companies can choose particular modules depending on their research interest and resources. The approach also allows the extension of additional modules. The complete explorative multimodular approach is initially tested and evaluated in one company. Modules 1-3 will be carried out in a large German leading global supplier of technology and services. The company employs roughly 400000 associates in approximately 60 countries worldwide, thereof 132000 in Germany in more than 100 locations where employees pursue a variety of professional activities differing in their work-related risk of infection with SARS-CoV-2. An additional fourth module (figure 1) will be conducted by the participating company's medical service. As the approach is transferable to other settings, the team of the IASV plans to extend this research design to other companies, institutions and public authorities. 


\section{Explorative modular mixed methods design}

Aim: Exploration of how companies adjust to new occupational health and safety standards designed to prevent the spreading of the COVID-19 disease.

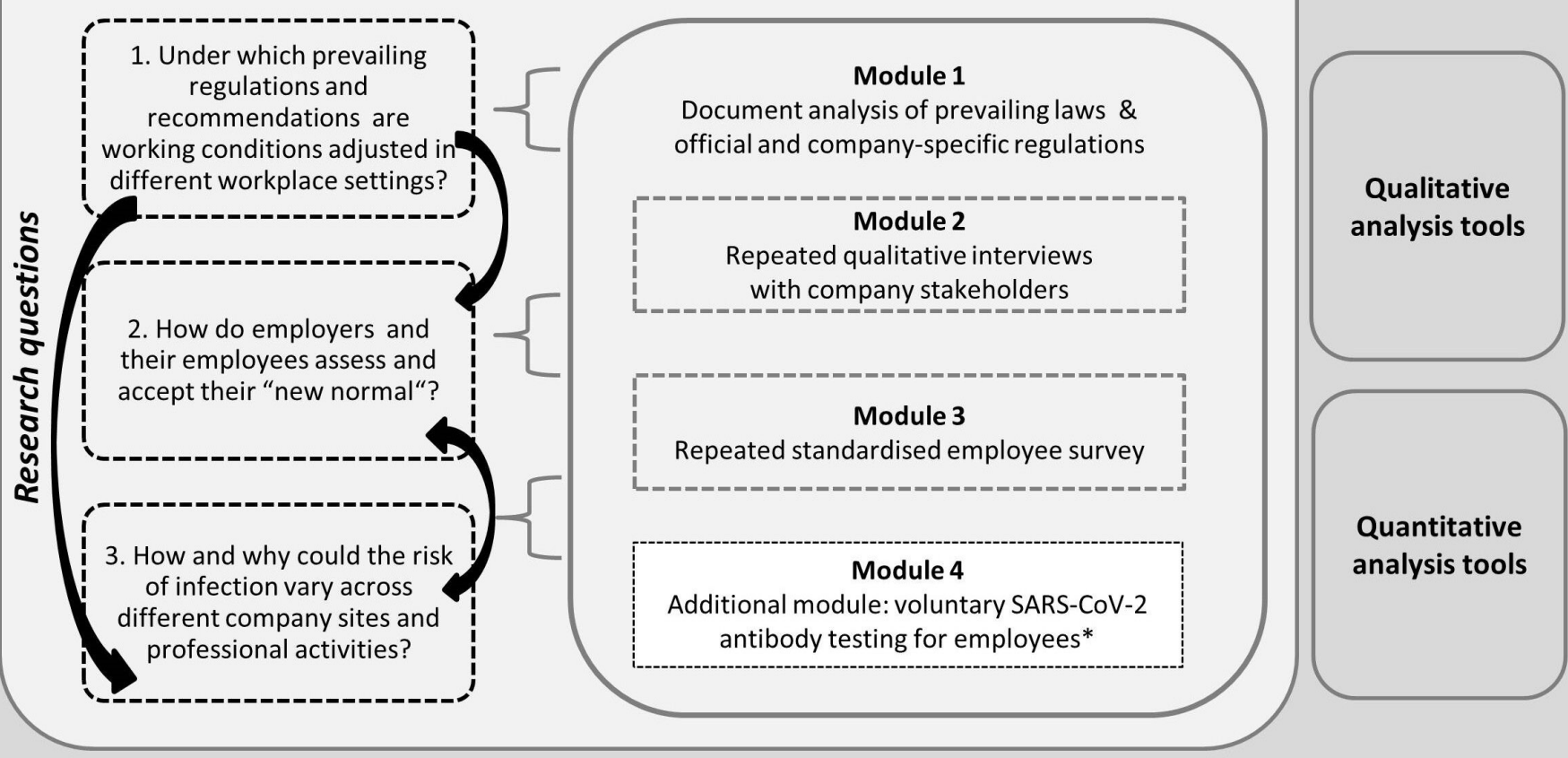

Data integration: all modules complement each other and the selection of the entire set will provide the most comprehensive understanding of the research questions.

Figure 1 Illustration of the applied explorative modular mixed methods design. *Additional module 4: service offered and conducted by the participating company's medical service.

In module 1, prevailing national and local laws as well as occupational health and safety regulations of the respective site will be analysed. In module 2, qualitative interviews with company stakeholders will be conducted at the beginning and in the middle of the survey period. In module 3, we will focus on the perspective of employees conducting three waves of a standardised survey. Module 4 will comprise SARS-CoV-2 antibody testing for employees offered as a voluntary occupational health service by the participating company and carried out by the company's medical service. Using these methods in combination, we expect to be able to provide different perspectives, explanations and a deeper understanding of how companies and their employees adjust to working conditions in Germany during the COVID-19 pandemic in particular ways and how different attitudes and behaviours may impact their perceived and measured risk of infection.

Each module can stand by itself; however, selecting the entire set (modules 1-3) or even extending it (module 4) will provide the most comprehensive understanding of the study objective. The initial company agreed to participate in modules 1-3 and to conduct module 4. Further companies can combine particular modules depending on their specific interests and resources. For example, if a company was particularly interested in why certain measures of infection protection during the COVID-19 pandemic may be accepted, ignored or rejected it would be advisable to take part at least in modules 1 and 3 . For a deeper understanding, it would also be advisable to include module 2 . In order to evaluate how and why the results of the antibody testing (module 4, carried out by the participating company) and the perceived risk of infection may vary across company sites or areas of professional activities, a combination of all modules or at least modules 1, 3 and 4 would be recommended. As all data collection methods complement each other, data integration (eg, converting coded qualitative data into variables for statistical analysis, ${ }^{21}$ triangulation of qualitative and quantitative data) depends on the number of modules in which a company chooses to participate. ${ }^{22}$

\section{Patient and public involvement}

Neither patients nor the public were and are involved in the planning of the design, the recruitment, instrument 
development, data analysis, and reporting or dissemination plans of this study.

\section{Study duration}

As the participating company will take part in the complete set of modules including multiple survey and blood sampling waves, we anticipate a study duration of 18 months (table 1). The actual survey period for the company is 13 months.

\section{Study procedures: setting, sampling, data collection and analysis}

As companies are responsible for occupational health and safety to protect their employees, company owners and executive managers play a crucial part in preparing and responding to disease outbreaks, such as the COVID-19 pandemic. ${ }^{23}$ This includes, for example, the adaption of workplace settings to protect workers, the development of action plans for resuming production after a period of closure or managing an increasing number of teleworkers. $^{7}$ Companies and their occupational health service have also been advised to prepare for the potential physical, mental and psychosocial effects of the "new normal' on employees. ${ }^{23}$

For all groups of employees, the working conditions are changing as a result of new infection control measures (eg, distance and hygiene rules, modification of work schedules). On the one hand, groups of employees are exposed to an increased work-related risk of infection due to the necessity of working on-site closely together with other personnel (eg, company medical service, plant security, personnel working on the assembly line). On the other hand, there are groups of employees (eg, administrative staff) who can also work from home. Although this reduces the work-related risk of infection, new physical and psychological burdens and challenges arise with regard to working conditions and work design (eg, ergonomically adequate workstations at home, organisation of childcare, dissolving boundaries between work and private life, loss of immediate team support).

To capture potential regional and activity-related differences in the occupational risk and perception of infection risk, purposive sampling ${ }^{24}$ will be used to include about six different company sites of the initially participating company. Inclusion criteria comprise a combination of sites providing the greatest possible contrast between different fields of activities (eg, personnel working in open-plan offices/telework vs personnel on the assembly line). Furthermore, the company sites' responsible executive managers, employee organisation and medical service will need to agree to the participation of the respective sites.

Module 1 is a continuous literature search and document analysis. ${ }^{25}$ The objective is to present workplacerelated, legal, infectiological and social conditions facing companies in the context of the COVID-19 pandemic following the first lockdown in Germany. Three researchers from the IASV analyse and discuss prevailing federal and regional laws (eg, from the Federal Ministry of Health and from the Federal Ministry of Labour and Social Affairs), the development of infection rates in Germany (eg, from the Robert Koch Institute), and occupational health and safety and infection control regulations at the respective sites of the participating company. This will provide a broader legal, infectiological and organisational cultural context for the interpretation of the results of the other modules. An information letter accompanied by a consent form will be sent to the responsible contact person (eg, executive manager). With the consent of the management and the employee organisation, the company will be invited to provide documents and a short questionnaire with general company information (eg, size of the company sites, number of employees in different departments and branches, job descriptions), and information on current implemented health and safety measures (eg, contact restrictions, telework regulations, working in fixed teams, implementation of hygiene rules). This information will also allow the calculation of response rates for modules 3 and 4 .

Module 2 will comprise qualitative interviews with key actors at different company sites (eg, executive managers, members of the employee organisation). The IASV will address them as experts of their respective departments who can provide an overview of daily working procedures and who are involved in problem solution processes. ${ }^{26}$ The interdisciplinary project team will develop a semistructured interview guide according to the SPSS method developed by Hellferich ${ }^{27}$ covering these topics:

- Workplace design and organisation of working procedures in the context of the COVID-19 pandemic.

- Assessment of work-related stress and strain.

- Expectations and attitudes towards infection control and occupational health and safety measures.

- Expectations and attitudes towards SARS-CoV-2 antibody tests.

Purposive sampling ${ }^{24}$ will be used to invite interview partners from different company sites and different fields of activities (eg, administrative responsibilities, organisation of work at the assembly line, provision of occupational health services) if they have worked at their current job for at least 6 months and have a knowledge of German at least at B1-level. ${ }^{28}$ The participants will receive information on interview procedures, data protection and data management accompanied by an individual consent form. We plan to conduct interviews with the same participants at the beginning and in the middle of the study period to capture potential changes in their experiences and attitudes. In the event of relevant changes in the incidence of infection (eg, local outbreak) or adjustment of company procedures (eg, new measures of infection protection), further interviews could be arranged. All interviews will be conducted by the team of the IASV. Based on experience from previous projects, the duration of the interviews will take about 30-45 minutes. ${ }^{29}$ Interviews will be audio taped and transcribed by a professional company according to a simplified system whereby transcription 


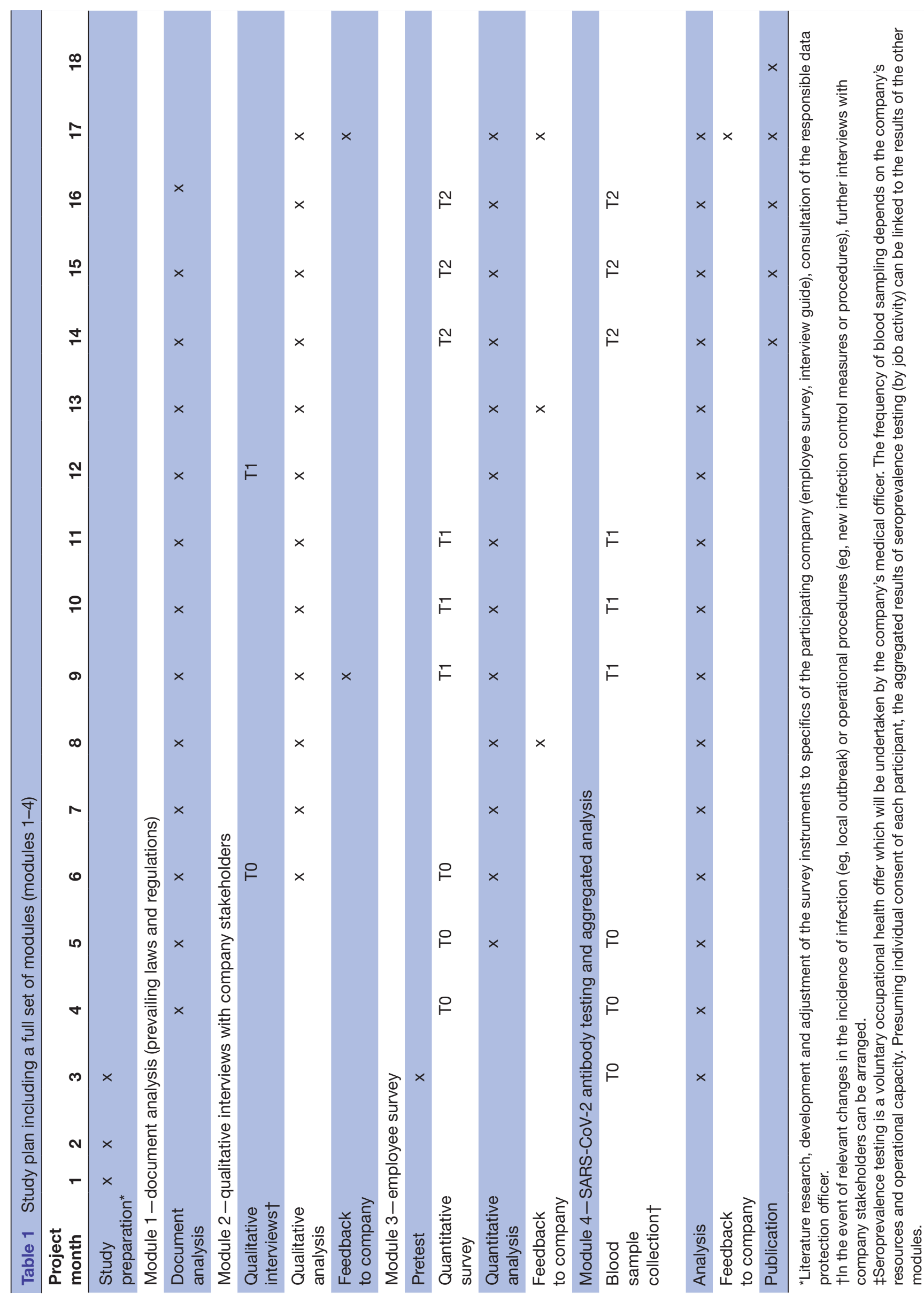

민

윰 
is word by word, but not phonetically. ${ }^{30}$ Quality checks, depersonalisation and pseudonymisation of the data will be undertaken by the team of the IASV conducting the interviews. Interviewees will have the opportunity to re-read their interviews and give feedback on passages they consider as risky. The data will be imported into MAXQDA, ${ }^{31}$ and analysis will be carried out by two researchers of the IASV following the steps of qualitative content analysis, including the development of a coding frame, the segmentation of the material, the testing of the coding frame, the evaluation of the trial coding and the completion of the main coding. ${ }^{32}$ Preliminary results will be presented to further members of the study team to discuss remaining open questions and ensure quality control. All data will remain at the IASV.

\section{Sample size}

If applicable, we plan to include two company sites and several fields of activity in each site (eg, production halls, open space offices, workplaces with high frequency of customer contacts) to the sample. We plan to conduct one interview per addressed field of activity at the time of the initial online survey (T0) and a follow-up interview with the same person after the second online survey (T1). The total number of interviews cannot be determined at this stage because it depends on the number of company sites included in the entire study. Due to a rather specific research aim, high sample specificity and quality of dialogue ${ }^{33}$ we assume eight participants per company will provide sufficient information for the aspired analysis. Thus, we expect a minimum number of 16 interviews to reach data saturation ${ }^{29}$ ( 4 interviewees at two company sites interviewed at the beginning and the end of the survey period).

Module 3 comprises three waves of a repeated standardised (anonymous) employee survey carried out by the IASV. T0 allows to capture the initial status in summer/ autumn 2020 in Germany. T1 will cover the winter months, while T2 will again be carried out in summer 2021. This approach makes it possible to identify different phases and probably also peaks during the ongoing COVID-19 pandemic. Closed and open questions on our questionnaire are being designed to capture potential changes in the participants' experiences and attitudes towards working conditions during the COVID-19 pandemic as well as their perceived risk of infection at the workplace and outside the working environment. ${ }^{34}$ Depending on the participating companies' preferences, a paper-based or online questionnaire is being developed. The questions are based on national and international recommendations regarding occupational health and safety standards and infection control measures, tailored to the risks of SARS-CoV-2 infection, ${ }^{6-8}$ established recommendations of evaluating work-related stress and strain, ${ }^{35}$ as well as existing questionnaires. ${ }^{36}$ According to the explorative design, we did not predefine one specific outcome, but addressed these aspects: the risk of infection perceived by employees, their experiences and attitudes towards infection protection at the workplace, and the associated psychological stress and strain. This will provide context to interpret the occurrence of infections (self-reported antibody status, aggregated results of antibody testing) as well as for recommendations concerning infection protection at the workplace. Main subject areas of the questionnaire are summarised in table 2 .

The questionnaire will be pretested by a group of academic volunteers as well as by representatives of the target audience. Participation in each survey wave is voluntary. Survey invitations will be organised by the participating company (eg, via company e-mail accounts, company newsletter, posters, postcards). Taking part requires employees to be of legal age with a knowledge of German at least at B1-level, ${ }^{28}$ and-in case of an online

Table 2 Subject areas and themes of the questionnaire

Subject areas Themes

Evaluation of implemented SARS-CoV-2-related For example, distance regulations, hygiene rules, organisation of telework and occupational health and safety standards teams working on-site, provision of protective equipment, workplace design

Evaluation of work-related stress and strain related to the COVID-19 pandemic

For example, work-related stress and strain before and during the COVID-19 pandemic concerning work content/task, organisation of work, working environment, social relations, new patterns of work

\section{Assessment of perceived and potential risk of infection at the workplace}

Assessment of perceived and potential risk of infection outside the working environment

Sociodemographic and medical information potentially related to the prevalence of SARSCoV-2 infections

Other relevant measures
For example, concern of being infected at the workplace, number of contacts with others, working in fixed teams, working on-site or at home, acceptance and practicability of hygiene rules at work (keeping distance, wearing masks)

For example, concern of being infected outside the working environment, number of social contacts, contact to risk groups, travel behaviour, practised leisure activities (low contact vs contact sports)

For example, age, sex, marital status, educational background, work experience, current occupation, number of children and their attendance in day-care centres or schools, relevant underlying medical conditions, if available: SARS-CoV-2 antibody status

For example, control measures for personality factors, resilience and social desirability 
survey-internet access via PC, tablet or smartphone. Individual consent to participate is given by the study participants after sufficient information on data protection and data management at the beginning of the survey. At the end of the first survey wave, participants will be asked to generate an 8-digit code which will be the same for all survey waves and can be used to merge the data of each person anonymously over subsequent survey waves. ${ }^{37}$ Participants can (but do not have to) provide the result of the seroprevalence testing to the questionnaire. The completion of the survey is expected to take approximately 25 minutes. In case of an online survey, the individual survey responses will be managed via the established online tool Unipark. ${ }^{38}$ In case of a paper-pencil questionnaire, each survey sheet will be scanned at the University Hospital Tübingen using an Optical Character Recognition system. ${ }^{39}$ All data will remain at the IASV and will be analysed applying appropriate descriptive and inferential statistics in SPSS. ${ }^{40}$ Depending on the sample size, a biometrician will be involved in discussing the development of hypothesis testing models which can be applied if a sufficient number of respondents take part in the survey.

\section{Sample size}

According to the exploratory design, we aim to invite the entire staff of the participating company sites $(n \sim 22$ $000)$. Stratification can only be carried out if a sufficient number of cases per subgroup is reached $(>=10)$.

Module 4: SARS-CoV-2 seroprevalence testing will be carried out as a voluntary company offer for employees by the occupational service of the participating company sites; hence, all individual data are subject to doctorpatient confidentiality and will remain with the participating company's medical service. In terms of quality assurance, the IASV research team will advise on database design, selection of antibody tests (type, pharmaceutical supplier) the content of a short participant questionnaire completed when blood sampling takes place (age, sex, work location, field of activity), and analysis procedures. Testing and aggregated epidemiological evaluations at the company level will be carried out according to applicable medical regulations. ${ }^{41}{ }^{42}$ Presuming individual consent of each participant, the results of the antibody tests (aggregated to company specific operational activities, eg, infections in open plan office vs assembly line) can be analysed in combination with the results of the other modules by the IASV. As module 4 is of exploratory nature, data will be analysed applying appropriate descriptive and inferential statistics in SPSS. ${ }^{40}$

\section{Sample size}

Due to the currently low prevalence of SARS-CoV-2 in Germany $(<2 \%),{ }^{43}$ serological diagnostic and hypothesis testing are only suitable for larger epidemiological studies including a sufficient number of cases allowing for stratification. For example, assuming a small effect size $\left(\eta^{2}=0.01\right)$ for the detection of potential differences in the seroprevalence across employees from four different areas of activity at a power of $80 \%$, statistical analysis would require a sample size of 271 persons per area of activity ( $\mathrm{n}=1084$ employees) to obtain a statistically significant result performing a single factor analysis of variance (ANOVA, $\alpha=0.05)^{44}$

\section{Data protection}

Relevant data protection regulations will be observed for all data collected and coordinated with the responsible ethics committee, academic and company data protection officers, as well as the respective company physicians and representatives of the employee organisation. Concerning module 1 , the company sites will decide whether and how they provide company-related information. All other data (eg, federal and regional COVID-19related regulations) are available publicly. Depending on the extent of the information provided by the companies and the official information available, the respective legal and organisational context of different workplace settings is compiled by the IASV.

Participants taking part in module 2 will provide individual consent to be interviewed by project members of the IASV. The digital audio recordings and original (non-pseudonymised) transcripts will be stored in the secure network of the University Hospital Tübingen and destroyed after the completion of the analyses. For the analysis, all names, places and references that would allow drawing conclusions about a person or the participating company or company site will be pseudonymised by project members of the IASV. The pseudonymised transcripts will only be accessible to project members of the IASV, stored in the secure network of the University Hospital Tübingen. All other persons will have access only to the interview excerpts cited in reports or publications. In terms of module 3 , the participants provide individual consent to take part in the anonymous employee survey. In case of an online survey, the questionnaire data will be collected via the established survey tool Unipark complying with security requirements according to the information security standard ISO/IEC $27001 .{ }^{45}$ In case of a paper-pencil questionnaire, all data will be scanned at the University Hospital Tübingen. ${ }^{39}$ All data will be transferred to SPSS $^{40}$ and stored in the secure network or a lockable archive of the University Hospital Tübingen. Individual data will only be accessible for project members of the IASV.

The collection and pseudonymisation of the individual serum samples during module 4 will be organised by the company's medical service and is subject to medical confidentiality. Presuming individual consent of each participant, project members at the University Hospital Tübingen will receive data on the seroprevalence of employees aggregated to areas of activity, also including aggregated demographic information (age, sex). If the response rate is low ( $\leq 10 /$ area of activity), these data will be aggregated with the data from other company sites and if necessary with other areas of activity. 
In line with the German guidelines for storing research data, ${ }^{46}$ all data compiled by the IASV (modules 1-3) as well as the aggregated data received by the participating company (module 4 ) will be stored for 10 years after the final publication in the secure network of the University Hospital Tübingen and destroyed thereafter. These data will be accessible only to IASV-personnel involved in the research project.

\section{ETHICS AND DISSEMINATION}

\section{Research ethical approval}

The study and all study-related documents were designed following the principles formulated in the current version of the Declaration of Helsinki. ${ }^{47}$ The approval of the study design was received in June 2020 from the responsible local ethical committee of the Medical Faculty, University of Tübingen and University Hospital Tübingen (No.: 423/2020BO).

\section{Progression of the study}

The development of the research instruments are in progress. The recruitment of the first wave of participants has commenced 21 July 2020 and is anticipated to continue until October 2020.

\section{DISSEMINATION}

Study results will be published in peer-reviewed journals and presented at international and national conferences.

\section{DISCUSSION}

There are some pros and cons associated with our study approach. Although the triangulation (and integration) of evidence is an integral part of mixed methods research, ${ }^{17}$ the design of our study is unique in terms of the modular approach we specifically developed for assessing how companies and their employees experience and adjust to working conditions in Germany during the COVID-19 pandemic. Furthermore, the design is transferable to other companies, institutions and public authorities in Germany. However, this is not an international study. Therefore, the gained results from Germany may not be translatable to other countries. Depending on their areas of interest and resources, the modular approach enables the implementation of up to three substudies conducted by the IASV, also allowing for a cross-sectional or a longitudinal study design with multiple survey and interview waves. Additional substudies such as SARS-CoV-2 seroprevalence testing can be implemented and conducted by the participating companies. Each of the quantitative (employee survey, SARS-CoV-2 antibody testing) and qualitative methods (document analysis, interviews with company stakeholders) applied can stand by itself; however, in linking different data sets and methods (document analysis, descriptive and interferential statistics, content analysis) as well as a variety of perspectives (researchers, company stakeholders, workers) the integration ${ }^{21}$ of the individual results will provide a detailed analysis of the overall research objective. In terms of resources (eg, time, required qualification of the personnel, organisational effort), we expect that the combination of the methods applied will mitigate some of the limitations inherent for quantitative (numeric description of phenomena, complexity of statistical analysis dependent on survey response rate, superficial understanding of participants' experiences, attitudes and causal relationships) and qualitative research (eg, small sample, results not statistically representative of a population, time consuming data collection and analysis). ${ }^{48}$

Finally, we want to highlight potential concerns of the participants that may occur over the course of the study. Since the company's medical service is involved in data collection (module 4), the participants may be concerned that their test results or their responses from the interviews and questionnaires (modules 2 and 3) have a negative impact on their working conditions or employment. We aim to avoid this issue by communicating our comprehensive data protection concept, by providing extensive information on the study, and by emphasising the participants' right to withdraw from the study without any negative consequences. The project leader and responsible researchers will also be available to answer questions occurring over the course of the study period. Furthermore, the pseudonymised (module 2) and non-aggregated anonymised (module 3) data remain exclusively at the Institute of Occupational Medicine, Social Medicine and Health Services Research, University Hospital Tübingen and will be evaluated there. The company (eg, company owners, executive managers, works council, company medical service) will only receive aggregated evaluations. With respect to the antibody testing (module 4), this offer will be a completely voluntary occupational health service for company employees, and the physician of the responsible medical service will provide information about the usual risks and side effects of blood sampling.

With this study, we aim to provide an in-depth analysis of occupational health and safety challenges related to the process of resuming and continuing work-related activities during the COVID-19 pandemic. This includes, for example, the consideration of work activities requiring on-site presence-possibly in close contact with colleagues, suppliers or the public-as well as issues associated with an increased use of telework. We expect that our study will contribute to the development of working conditions ensuring that job-related activities can be designed as safe as possible to the requirements of occupational health and safety regulations and to the particular needs of companies and their employees.

\section{Author affiliations}

${ }^{1}$ Institute of Occupational and Social Medicine and Health Services Research, University Hospital Tübingen, University of Tübingen, Tübingen, Germany

${ }^{2}$ Medical Services, Robert Bosch GmbH, Stuttgart, Germany

${ }^{3}$ Coordination Centre, Core Facility for Health Services Research, University of Tübingen, Faculty of Medicine, Tübingen, Germany 
Acknowledgements Thanks to our cooperation partners, the responsible ethics committee and the data protection officers who provided valuable advice on the study design. The authors would also like to thank Benjamin Lee for his linguistic advice on the manuscript.

Contributors All authors contributed to the development of the study design. ER, $\mathrm{CP}, \mathrm{AW}, \mathrm{AS}, \mathrm{BS}$ and MAR conceptualised modules 1-3 and KK, FP, KA, AK and JK had the initial idea for module 4. ER and MAR were involved in obtaining approval from the Ethics Committee of the Medical Faculty, University Hospital of Tübingen. ER is the primary investigator and drafted the manuscript. All authors provided critical feedback on the manuscript, read and approved the final version.

Funding The testing of antibodies against SARS-CoV-2 (module 4) will be financed by the participating companies themselves. The work of the Institute of Occupational and Social Medicine and Health Services Research Tübingen is supported by an unrestricted grant of the Employers' Association of the Metal and Electric Industry Baden-Württemberg (Suedwestmetall: D30.11909). The authors gratefully acknowledge support by the Open Access Publishing Fund of the University of Tübingen.

Disclaimer The funding sources had no role in the design of the study and will not be involved in the conduct, collection, management, analysis, interpretation or dissemination of any data or results of the research.

Competing interests None declared.

Patient consent for publication Not required.

Provenance and peer review Not commissioned; externally peer reviewed.

Supplemental material This content has been supplied by the author(s). It has not been vetted by BMJ Publishing Group Limited (BMJ) and may not have been peer-reviewed. Any opinions or recommendations discussed are solely those of the author(s) and are not endorsed by BMJ. BMJ disclaims all liability and responsibility arising from any reliance placed on the content. Where the content includes any translated material, BMJ does not warrant the accuracy and reliability of the translations (including but not limited to local regulations, clinical guidelines, terminology, drug names and drug dosages), and is not responsible for any error and/or omissions arising from translation and adaptation or otherwise.

Open access This is an open access article distributed in accordance with the Creative Commons Attribution Non Commercial (CC BY-NC 4.0) license, which permits others to distribute, remix, adapt, build upon this work non-commercially, and license their derivative works on different terms, provided the original work is properly cited, appropriate credit is given, any changes made indicated, and the use is non-commercial. See: http://creativecommons.org/licenses/by-nc/4.0/.

ORCID iD

Esther Rind http://orcid.org/0000-0001-8200-4862

\section{REFERENCES}

1 World Health Organization. Coronavirus. Available: https://www.who. int/health-topics/coronavirus\#tab=tab_1 [Accessed 19 May 2020].

2 Dorn F, Khailaie S, Stöckli M. The common interest of health and economy: A scenario calculation for the containment of the corona pandemic. A joint study of the ifo Institute (ifo) and the Helmholtz Centre for Infection Research (HZI). In: Ifo Schnelldienst digital. München: ifo Institut, 2020.

3 Tagesschau. [VW shutting down again - news from 13.05.2020]. Available: https://www.tagesschau.de/wirtschaft/vw-produktion-105. html [Accessed 19 May 2020].

4 Veitinger T. [Bosch - environmental protection despite pandemic. Heidenheim News from 30.04.2020]. Available: https://www.hz.de/ wirtschaft/wirtschaft-ueberregional/umweltschutz-trotz-pandemie45870919.html [Accessed 19 May 2020].

5 Verma S, Gustafsson A. Investigating the emerging COVID-19 research trends in the field of business and management: a bibliometric analysis approach. J Bus Res 2020;118:253-61.

6 Cirrincione L, Plescia F, Ledda C, et al. COVID-19 pandemic: prevention and protection measures to be adopted at the workplace. Sustainability 2020;12:3603.

7 EU-OSHA. EU Guidance. Covid-19: back to the workplace. adapting workplaces and protecting workers. EU-OSHA,European Agency for Safety and Health at Work, 2020.

8 Federal Ministry of Labour and Social Affairs. [SARS-CoV-2Occupational Safety Standard from 16.04.2020]. Available: https:// www.bmas.de/SharedDocs/Downloads/DE/PDF-Schwerpunkte/
sars-cov-2-arbeitsschutzstandard.pdf?_blob=publicationFile $\& \mathrm{v}=4$ [Accessed 19 May 2020].

9 Haghani M, Bliemer MCJ, Goerlandt F, et al. The scientific literature on coronaviruses, COVID-19 and its associated safety-related research dimensions: a scientometric analysis and scoping review. Saf Sci 2020;129:104806.

10 Ambigapathy S, Rajahram GS, Shamsudin UK, et al. How should front-line general practitioners use personal protective equipment (PPE)? Malays Fam Physician 2020;15:2-5.

11 Chen Y, Pradhan S, Xue S. What are we doing in the dermatology outpatient department amidst the raging of the 2019 novel coronavirus? J Am Acad Dermatol 2020;82:1034.

12 Cheung JC-H, Ho LT, Cheng JV, et al. Staff safety during emergency airway management for COVID-19 in Hong Kong. Lancet Respir Med 2020;8:e19.

13 Alahmad B, Kurdi H, Colonna K, et al. COVID-19 stressors on migrant workers in Kuwait: cumulative risk considerations. BMJ Glob Health 2020;5:e002995.

14 Lemke MK, Apostolopoulos Y, Sönmez S. A novel COVID-19 based truck driver syndemic? implications for public health, safety, and vital supply chains. Am J Ind Med 2020;63:659-62.

15 Lemke MK, Apostolopoulos Y, Sönmez S. Syndemic frameworks to understand the effects of COVID-19 on commercial driver stress, health, and safety. $J$ Transp Health 2020;18:100877.

16 Rafeemanesh E, Ahmadi F, Memarzadeh M. A review of the strategies and studies on the prevention and control of the new coronavirus in workplaces. Arch Bone Jt Surg 2020;8:242-6.

17 Mayring P. [Triangulation of evidence and mixed methods in health research]. In: Haring R, ed. Health sciences. Berlin Heidelberg: Springer, 2019: 133-41.

18 Niederberger M, Peter L. [Mixed methods studies in the health sciences. A critical map]. Z Evid Fortbild Qual Gesundhwes 2018;133:9-23.

19 O'Cathain A, Murphy E, Nicholl J. The quality of mixed methods studies in health services research. $J$ Health Serv Res Policy 2008:13:92-8.

20 Tariq S, Woodman J. Using mixed methods in health research. JRSM Short Rep 2013;4:2042533313479197.

21 Bryman A. Integrating quantitative and qualitative research: how is it done? Qualitative Research 2006;6:97-113.

22 Fielding NG. Triangulation and mixed methods designs. J Mix Methods Res 2012;6:124-36.

23 Fadel M, Salomon J, Descatha A. Coronavirus outbreak: the role of companies in preparedness and responses. Lancet Public Health 2020;5:e193.

24 Guetterman TC. Descriptions of sampling practices within five approaches to qualitative research in education and the health sciences. Forum: Qualitative Social Research.16, 2015. Available: http://nbn-resolving.de/urn:nbn:de:0114-fqs1502256

25 Wolff S. [Analysis of documents and field analyis]. In: Flick U, von Kardorff E, Steinke I, eds. [Qualitative research a manual. 5th ed]. Reinbek bei Hamburg: Rowohlt Taschenbuch Verlag, 2007: 502-13.

26 Britten N. Qualitative interviews in medical research. BMJ 1995;311:251-3.

27 Hellferich C. The quality of qualitative data. manual for conducting qualitative interviews. Wiesbaden: VS Verlag für Sozialwissenschaften, 2004

28 Council of Europe. Common European framework of reference for languages (CEFR). Available: https://www.coe.int/en/web/commoneuropean-framework-reference-languages [Accessed 21 Jul 2020].

29 Aldiabat KM, Le Navenec C. Data saturation: the mysterious step in grounded theory methodology. The Qualitative Report 2018;23:245-61.

30 Dresing T, Pehl T. Research in practice: interviews, transcription $\&$ analysis. In: Instructions and control systems for qualitative researchers. 8th ed. Marburg: dr dresing \& pehl GmbH, 2018.

31 MAXQDA. The art of data Analyis. Available: https://www.maxqda. com/how-to-analyse-qualitative-data [Accessed $25 \mathrm{Jan}$ 2020].

32 Schreier M. Qualitative content analysis in practice. London: Sage, 2012.

33 Malterud K, Siersma VD, Guassora AD. Sample size in qualitative interview studies: guided by information power. Qual Health Res 2016;26:1753-60.

34 Taddicken M. [Online-Survey]. In: Möhring W, Schlütz D, eds. Handbook of standardised survey procedures in communication science. Wiesbaden: Springer Fachmedien Wiesbaden, 2013: 201-17.

35 Gemeinsame Deutsche Arbeitsschutzstrategie (GDA). Occupational Safety and Health in Practice. In: Recommendations for implementing psychosocial risk assessment. Berlin: Management of 
the GDA Mental Health Working Programme, c/o Federal Ministry of Labour and Social Affairs, 2014.

36 COSMO open. COVID-19 Snapshot Monitoring (COSMO) [Questionnaires 2020]. Available: https://dfncloud.uni-erfurt.de/s/ Cmzfw8fPRAgzEpA [Accessed 25 May 2020].

37 Justus-Liebig-Universität Giessen. Code for panel studies. Available: https://www.uni-giessen.de/org/admin/stab/stl/servicestelle/ panelcode [Accessed 21 May 2020].

38 UNIPARK \& questback. [Developing Online-Surveys easily]. Available: https://www.unipark.com/?gclid=EAlalQobChMliL3u9o7P6QIViK3t Ch2cpgD-EAAYASAAEgKa9_D_BwE [Accessed 25 May 2020].

39 OCR System GmbH. OCR System. Available: https://www.ocrsysteme.de/en/ [Accessed 14 Aug 2020].

40 IBM. SPSS software. Available: https://www.ibm.com/analytics/spssstatistics-software [Accessed 21 Jul 2020].

41 Federal Ministry of Justice and Consumer Protection \& Federal Office of Justice. Ordinance on occupational health care (ArbMedVV). Available: https://www.gesetze-im-internet.de/englisch_arbmedvv/ index.html [Accessed 19 May 2020].

42 Federal Ministry of Justice and Consumer Protection \& Federal Office of Justice. Act on occupational physicians, safety engineers and other occupational safety specialists. Available: https://www. gesetze-im-internet.de/asig/ [Accessed 19 May 2020].

43 Blankenfeld H, Grill E, Kaduszkiewicz H, et al. Antibody Assays Against SARS-CoV-2: Why a Good Test Does not Always Produce Proper Results]. ZFA 2020;96:230-3.

44 Hemmerich WA. [StatistikGuru: Calculating sample size for single factor ANOVA]. Available: https://statistikguru.de/rechner/ stichprobengroesse-einfaktorielle-anova.html [Accessed 26 May 2020].

45 UNIPARK \& questback. [Data protection]. Available: https://www. unipark.com/datenschutz/ [Accessed 20 May 2020].

46 Deutsche Forschungsgemeinschaft (DFG). [Guideline for storing research data]. Available: https://www.dfg.de/download/ $\mathrm{pdf} /$ foerderung/antragstellung/forschungsdaten/richtlinien forschungsdaten.pdf [Accessed $21 \mathrm{Jul}$ 2020].

47 World Medical Association. World Medical association Declaration of Helsinki: ethical principles for medical research involving human subjects. JAMA 2013;310:2191-4.

48 Vanderstoep SW, Johnston DD. Research methods for everyday life: blending qualitative and quantitative approaches. San Francisco: Jossey-Bass, 2009. 